\title{
Studies on Molecular Composite IV. Block Copolymer as a Single-Component Nano Composite Consisting of Poly( $p$-phenylene benzobisthiazole) and Thermoplastic Aromatic Polyamide
}

\author{
Hiroshi AkITA and Hiroto Kobayashi \\ Fundamental Research Division, Wako Research Center, Honda R\&D Co., Ltd., \\ Chuo, Wako-shi 351-0193, Japan
}

(Received February 17, 1999)

\begin{abstract}
KEY WORDS Two-Step Synthesis / Polybenzothiazoles / Copolymerization / Nano Composites / Aromatic Polyamide / Network Structure /
\end{abstract}

The efficiency of reinforcing fiber in fiber-reinforced polymers depends on the ratio of the length to the diameter (L/D ratio) of the fiber. ${ }^{1}$ Molecular composites and nano composites are polymer blend materials consisting of a reinforcing polymer with a rod-like molecular structure finely dispersed in a flexible matrix polymer and having a high $\mathrm{L} / \mathrm{D}$ ratio. ${ }^{2,3}$

Poly ( $p$-phenylene benzobisthiazole) (PBZT) is a heterocyclic polymer with a rod-like molecular structure and its theoretical tensile modulus is $370 \mathrm{Gpa}^{4,5} \mathrm{We}$ synthesized a precursor polymer of PBZT and investigated applications as the reinforcing material in molecular composites and nano composites. ${ }^{6-10}$ The precursor polymer was an aromatic polyamide which had organic side chains and could be converted to PBZT by removing the side chains. It was then subjected to heat treatment at approx. $350^{\circ} \mathrm{C}$ for the formation of the fivemembered rings. ${ }^{6,7}$ The precursor polymers had good affinity with matrix aromatic polyamides which had molecular structures similar to that of the principal chain of the precursor polymer. ${ }^{8}$ These polymers could be blended using an organic solvent, and blended materials with finely dispersed precursor polymer were obtained. ${ }^{8,9}$ The precursor polymer could undergo thermal isomerization to PBZT in the solid composite state. ${ }^{9}$ The possibility that the fine phase structure of polymer composite is maintained is shown, even after heat molding at above the melting temperature of the thermoplastic matrix polymer, due to the fact that the use of a PBZT random copolymer as the reinforcing polymer introduced a fragment which has the same molecular structure as the matrix polymer. ${ }^{9}$ Ultimately, a matrix polymer of thermoplastic aromatic polyamide and a reinforcing polymer of the PBZT random copolymer were blended, followed by molding for obtaining PBZT nano composite materials. ${ }^{10}$ Two nano composites with different phase structures were obtained due to varied bulk molding process conditions. One bulk specimen was formed by PBZT uniformly dispersed as particles with approx. 30 nanometer diameter in the matrix polymer, and another type of specimen formed by a three-dimensional (3-D) network structure of PBZT fibrils with 30-60 nanometer diameter was also obtained.

As another approach to polymer micro composite material, copolymerization of rod-like polymers with different polymers was done. ${ }^{11-13}$ Dotrong et al. synthesized a graft copolymer consisting of poly(ether ketone) (PEK) side chains attached to PBZT and called it "Single-Component Molecular Composite". ${ }^{13}$ We attempted to produce two single-component nano composite materials and report the relationship between the mechanical properties and phase structure.

\section{EXPERIMENTAL}

\section{Materials}

Diamine monomer of the PBZT precursor, block copolymers (Figure 1) and random copolymers (Figure 2) were synthesized as described previous papers. ${ }^{8,9} \mathrm{We}$ used 3-chloro-terephthalic acid chloride (Tokyo-Kasei), an acid chloride monomer substituted with one $\mathrm{Cl}$ atom, to improve the solubility of obtained precursor

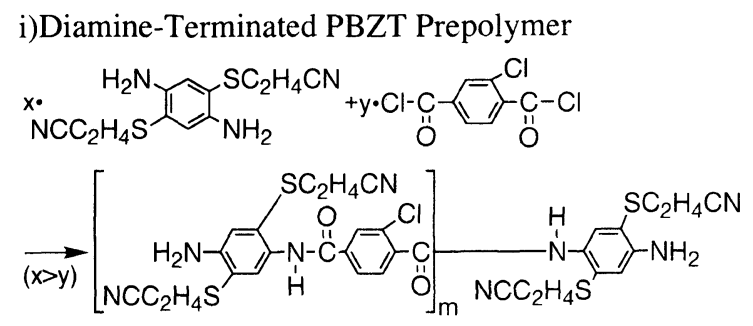

ii)Diacid Chloride-Terminated Aramid

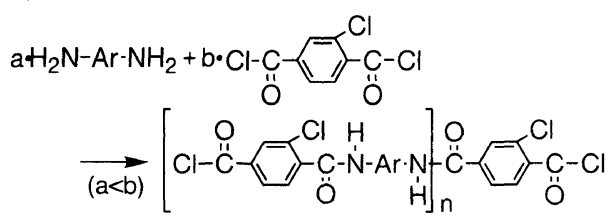

iii)Copolymerzation

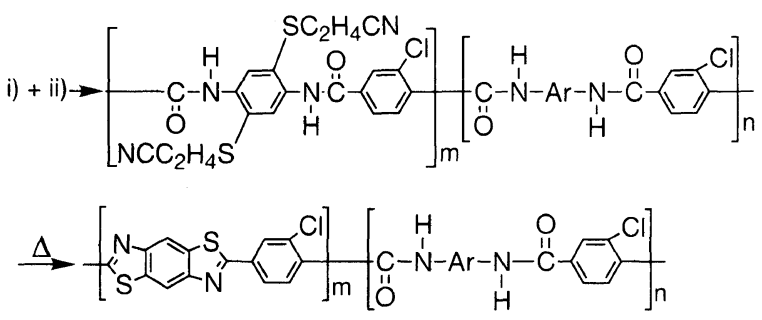

Figure 1. Synthesis of block copolymer of PBZT precursor and cyclization. "Ar" is the aromatic group shown in Figure 3. 


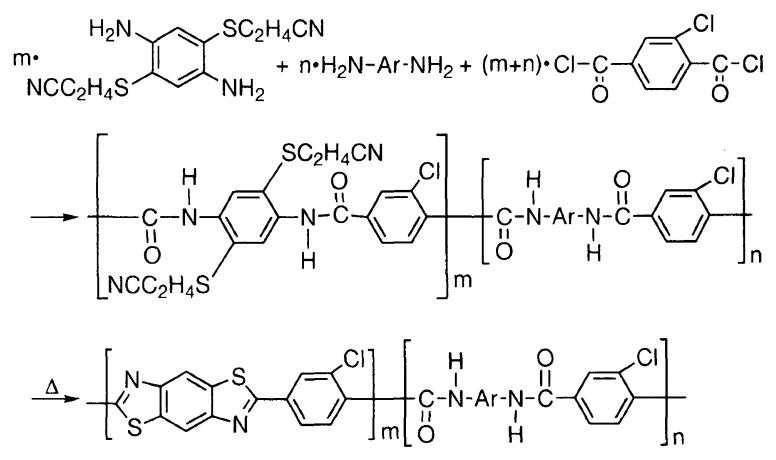

Figure 2. Synthesis of random copolymer of PBZT precursor (top and middle) and cyclization (bottom). "Ar" is the aromatic group shown in Figure 3.

polymers in organic solvent. Flexible aramid homopolymer was synthesized by low-temperature solution polymerization.

Consolidating of the block copolymer was performed as follows. The PBZT precursor copolymer was dissolved in $N$-methyl-2-pyrrolidone (NMP). The mixture was stirred at $80^{\circ} \mathrm{C}$ to produce a single-phase solution, followed by coagulation which produced a fine powder upon spraying into excess EtOH. The powder was washed with $\mathrm{EtOH}$ and dried in vacuum. To produce a bulk specimen consisting of a nano composite with finely dispersed particles of PBZT, the powder was heat treated at $330^{\circ} \mathrm{C}$ in vacuum for $30 \mathrm{~min}$ to convert the precursor to PBZT, followed by consolidation at $350^{\circ} \mathrm{C}$ in a closed mold with $9.8 \mathrm{MPa}$ of pressure, and then cooled. Bulk specimens were $80 \times 15 \times 2$ millimeters in size. To obtain a bulk specimen consisting of a nano composite having a 3-D network structure of PBZT, the powder (not previously heat treated) was consolidated at $230^{\circ} \mathrm{C}$ in a mold with $9.8 \mathrm{MPa}$ of pressure, followed by temperature ramping to $350^{\circ} \mathrm{C}$ to convert the precursor to $\mathrm{PBZT}$, in the closed mold with 4.9 MPa of pressure. Polymer blend materials consisting of the flexible matrix homopolymer and the PBZT precursor random copolymer were obtained as described in previous papers ${ }^{11}$ and molded using same process with that for block copolymers.

\section{Measurements}

Thermal gravimetric analysis (TGA) was performed using a RIGAKU TAS-200 thermal analyzer in nitrogen atmosphere with the temperature ramping rate of $10^{\circ} \mathrm{C}$ $\min ^{-1}$. Temperatures at which the cyclization of the precursor included in the copolymers was completed, resulting in the conversion to PBZT, was measured by observing temperature of initial weight loss in the TGA curve due to elimination of side chains of the precursor in the formation of five-membered rings of PBZT. Flexural properties of the consolidated specimen were determined using a universal test machine (Shimadzu AG-5000) in the three-point bending test at $25^{\circ} \mathrm{C}$. Phase structures of the nano composite samples were observed using a transmission electron microscope (TEM, Philips CM-120 STEM-TWIN) with accelerating voltage of 80 $\mathrm{kV}$ without staining. Thermomechanical analysis, such as determination of Vicat softening temperature and coefficient of linear expansion, was carried out using the RIGAKU TAS-200 TMA with the temperature
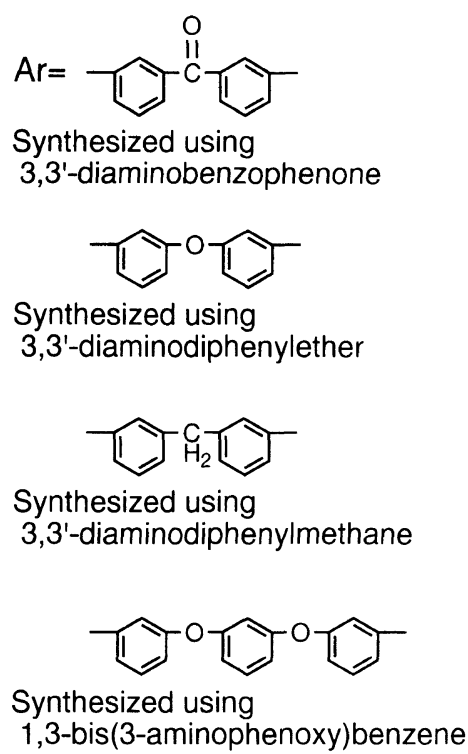

Figure 3. Structure of "-Ar-" in Figures 1 and 2.

Table I. Inherent viscosity of PBZT prepolymer oligomers for different amounts of acid chloride used for synthesizing the PBZT precursor oligomer from stoichiometry

\begin{tabular}{cc}
\hline Amount of sifted acid chloride & $\begin{array}{c}\text { Inherent viscosity of PBZT } \\
\text { prepolymer (in NMP, 30 }\end{array}$ \\
\cline { 1 - 1 } wt $\%^{\circ} \mathrm{C}$ )
\end{tabular}

ramping rate of $10^{\circ} \mathrm{C} \mathrm{min}^{-1}$.

\section{RESULTS AND DISCUSSION}

Synthesizing of Thermoplastic PBZT Block Copolymers

PBZT copolymers using 3,4'- or 4,4'-diaminodiphenylether monomers could not be molded by heat, ${ }^{8,9}$ but block copolymers changed the molecular structure of the aramid oligomer so that it became more flexible and could be molded without blending with the matrix polymer. Fragments of aramid used in the copolymerization in this study are shown in Figure 3. Obtained block copolymers with molar ratio of the PBZT precursor $v s$. the aramide fragment in the copolymer was $4: 6$ could be molded to give bulk specimens.

In synthesizing the block copolymers, we used different amounts of acid chloride used for synthesizing the PBZT precursor oligomer from stoichiometry to control the molecular weight of the oligomers. Inherent viscosity of the resultant PBZT prepolymer oligomers is indicated in Table I. $20 \mathrm{~mol} \%$ shift was used in the copolymerization in this study. Inherent viscosity of obtained block copolymers is indicated in Table II.

For polyimide, the heat-treatment temperature required to convert the precursor polymer (polyamic acid) to rigid-rod polyimide depends on the rigidity of the 
Table II. Inherent viscosity of block copolymers synthesized using several aromatic diamine and PBZT precursors at various partial molar ratios

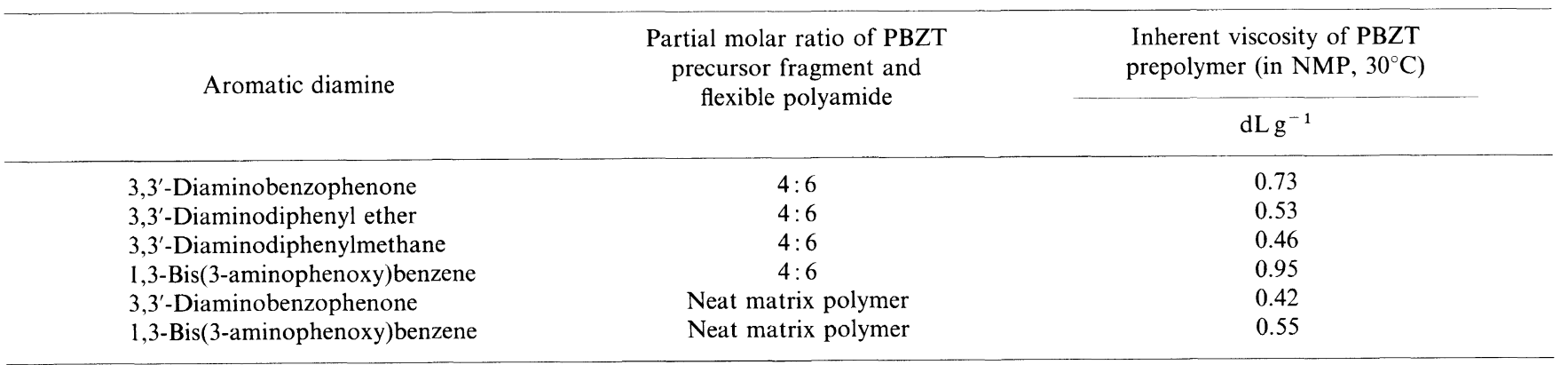

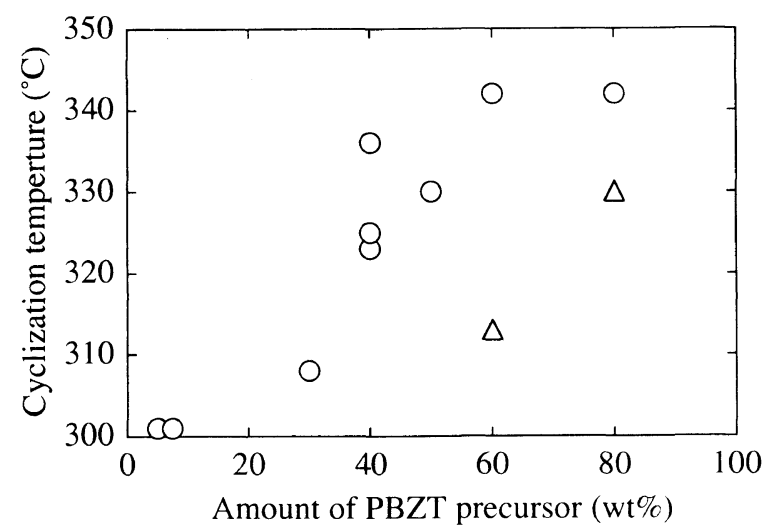

Figure 4. Temperatures at which PBZT precursor included in copolymers was converted to $\operatorname{PBZT}(O$, block copolymer; $\triangle$, random copolymer).

molecular structure of the polyimides obtained finally. ${ }^{14}$ This is presumed to be due to the fact that a certain degree of freedom of movement in the molecular chain of the polyamic acid is required to enable progress of the cyclization to form five-membered rings of the rigid-rod polyimide, and this tendency corresponds to that of the cyclization of the PBZT precursor copolymers to form five-membered rings of PBZT copolymers. Temperatures at which the conversion of the PBZT precursor was completed are plotted in Figure 4 against the partial molar quantity of the PBZT precursor contained in the copolymers. The temperatures for block copolymers are plotted in a temperature region higher than that for the random copolymers with the same molar ratio. This suggests that for block copolymers which contain fragments of PBZT as oligomers with higher polymerization degree than that of the random copolymers and restricted certain degree of freedom of movement of the molecular chain of the PBZT fragments, decrease in the rigidity of the molecular structure is less than that in the case of the random copolymers.

\section{Relationship between Phase Structure and Molding Conditions}

Conversion of the precursor to PBZT in the copolymer occurred in a higher temperature region (approx. $\left.250-330^{\circ} \mathrm{C}\right)^{6,7}$ than that for melting temperature of the flexible aramid segment (approx. $230^{\circ} \mathrm{C}$ ). Therefore, it is concluded that the timing of the conversion during the entire process of producing a bulk specimen of the nano composite is an important factor governing the phase structure of the bulk product finally obtained.

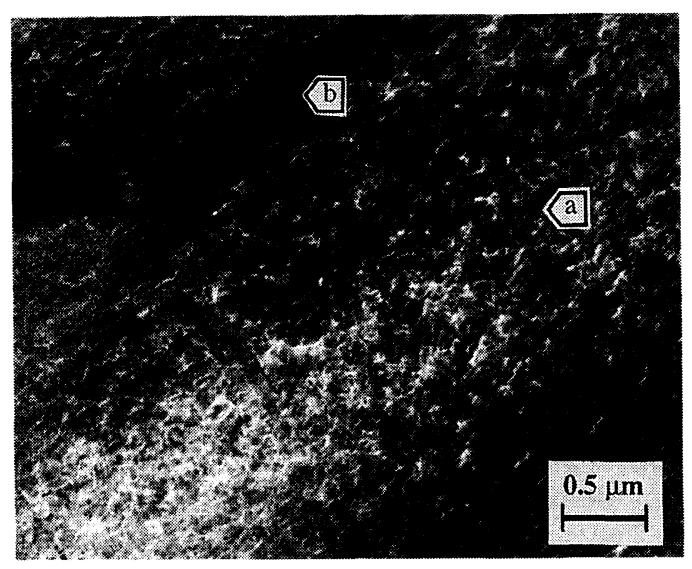

Figure 5. TEM image of phase structure of nano composite obtained by molding block copolymer consisting of PBZT rich phase dispersing fine particles of PBZT in aramid (a) and aramid rich phase (b). The dark regions are PBZT particles.

The phase structure of the bulk specimen obtained by means of heat treatment of the block copolymer powder synthesized using the PBZT precursor and 3,3'diaminobenzophenone to convert the precursor to PBZT, followed by molding, was observed using TEM and is shown in Figure 5. For the used block copolymer, the partial molar ratio of the PBZT precursor fragment and the flexible polyamide was $4: 6$. The bulk specimen had two phase structures consisting of an aramide-rich phase and a PBZT-rich phase, and PBZT particles with approx. 30 nanometer diameter were uniformly dispersed in the PBZT-rich phase.

A comparison of single component nano composites with polymer blend composites was made. The PBZT precursor block copolymer comprising 1,3-bis(3-aminophenoxy)benzene was synthesized. The aramid matrix homopolymer and PBZT precursor random copolymer which comprised the aramid fragment was synthesized and blended. The flexural modulus of molded specimens is plotted in Figure 6 against amount of PBZT contained in several specimens. No major differences regarding reinforcing effects between the single component nano composite and the polymer blended nano composite were observed.

As another molding process, the molding of a powder not previously heat treated at the melting point of the flexible segment was done, followed by raising the mold temperature to convert the precursor to PBZT, while it was still pressed in the closed mold. In this case, gases generated in the mold by the conversion of the precursor 
caused the polymer materials to flow out from the mold, which restricted the progress of the cyclization to PBZT to below approx. $50 \%$ of the precursor in the powder charged into the mold. The phase structure of the bulk specimen obtained by molding the block copolymer powder synthesized using the PBZT precursor and 3,3'diaminobenzophenone was observed using TEM and is shown in Figure 7. For the used block copolymer, the partial molar ratio of the PBZT precursor fragment and flexible polyamide was $4: 6$. A completely different structure consisting of continuous fibrils of PBZT with

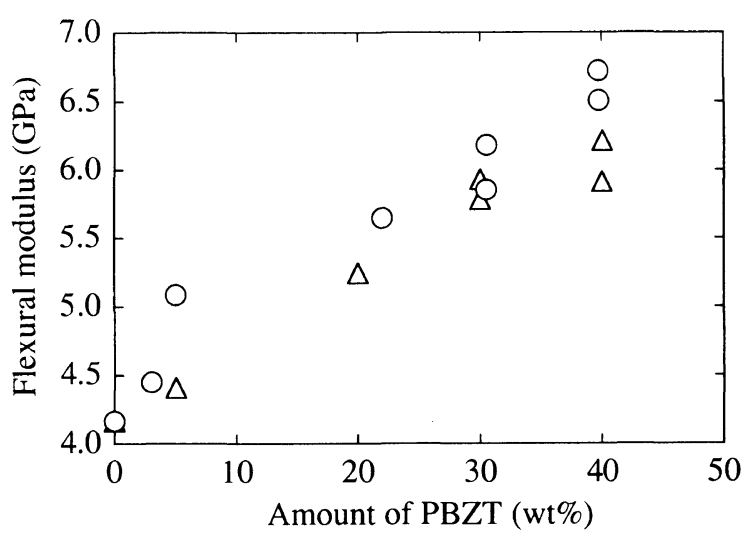

Figure 6. Flexural modulus of PBZT nano composite consisting of fine particles of PBZT obtained by molding block copolymers or polymer blend materials using random copolymer $(O$, block copolymer; $\triangle$, polymer blend material).

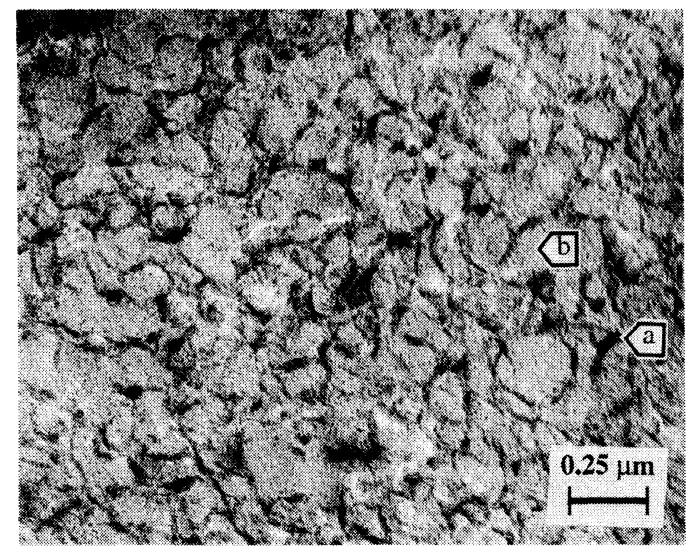

Figure 7. TEM image of phase structure of nano composite obtained by molding block copolymer consisting of 3-D network structure of PBZT (a) in aramid (b). The dark regions are PBZT fibrils. approximately 30 nanometer diameter, forming a 3-D network structure in the matrix polymer was observed.

These phase structures were essentially the same as structures obtained by means of polymer blending of a matrix polymer of thermoplastic aromatic polyamide and a reinforcing polymer of a random copolymer consisting of a precursor of PBZT and a fragment in common with the matrix polymer, followed by conversion of the precursor to PBZT and molding using the same methods identified using energy dispersive X-ray spectra (EDX) elemental analysis of each phase. ${ }^{11}$ But only in the case of the 3-D network structure, the size of the network structure was smaller than that of the structure obtained by consolidating the polymer blend material, indicating the effect of copolymerization.

\section{Relationship between Shape of Dispersed PBZT and Mechanical Properties}

Various mechanical properties of bulk specimens consisting of nano composites especially with "3-D network" phase structure, were evaluated. In all experiments, except for determination of flexural properties, the partial molar ratio of the PBZT precursor fragment and flexible polyamide was $4: 6$. PBZT amount of specimens with a PBZT 3-D network structure was below approx. $50 \mathrm{wt} \%$ of the copolymerized PBZT precursor, because cyclization in a closed mold was restricted to below approximately half the amount of the precursor due to reaction gas generation.

Chemical Resistance. The stability of the specimen with a 3-D network structure was significantly improved such that etching by NMP, concentrated sulfonic acid or methansulfonic acid was impossible. Matrix polymers of all other specimens were easily dissolved in these solvents.

Flexural Properties. The flexural modulus of the specimens with various diamine fragments and phase structures are indicated in Table III. Several diamine monomers were used to obtain specimens with finely dispersed PBZT. Because the PBZT precursor block copolymer synthesized using 3,3'-diaminobenzophenone demonstrated a slightly higher flexural modulus than that synthesized using another diamine monomer, we performed further investigation using the block copolymer. This diamine monomer has a higher density of unshared electron pairs belonging to the carbonyl group than other diamines, and should thus increase inter-

Table III. Flexural modulus of bulk specimens obtained by molding block copolymers synthesized using several aromatic diamine and PBZT precursors at various partial molar ratios

\begin{tabular}{|c|c|c|c|}
\hline \multirow{2}{*}{ Type of phase structure } & \multirow{2}{*}{ Aromatic diamine } & PBZT amount & \multirow{2}{*}{$\begin{array}{c}\text { Flexural modulus } \\
\mathrm{GPa}\end{array}$} \\
\hline & & $\%$ & \\
\hline \multirow{4}{*}{$\begin{array}{l}\text { Nano composite with dispersed fine } \\
\text { particles }\end{array}$} & 3,3'-Diaminobenzophenone & 34.7 & 6.99 \\
\hline & $3,3^{\prime}$-Diaminodiphenyl ether & 35.6 & 6.69 \\
\hline & 3,3'-Diaminodiphenyl methane & 33.0 & 6.61 \\
\hline & 1,3-Bis(3-aminophenoxy)benzene & 30.5 & 5.84 \\
\hline \multirow{2}{*}{ Neat matrix polymer } & 3,3'-Diaminobenzophenone & 0 & 5.30 \\
\hline & 1,3-Bis(3-aminophenoxy)benzene & 0 & 4.68 \\
\hline
\end{tabular}

${ }^{a}$ In case of molding of nano composite with PBZT 3-D network structure, gases generated in the mold by conversion of the precursor cause the polymer materials to flow out from the mold, thus restricting the cyclization to PBZT to less than approx. $50 \%$ of the precursor in the powder charged into the mold. 
Table IV. Mechanical properties at high temperature for PBZT 3-D network nano composite materials obtained by molding block copolymer consisting of PBZT precursor and thermoplastic polyamide

\begin{tabular}{ccc}
\hline & $\begin{array}{c}\text { Softening } \\
\text { temperature }\end{array}$ & $\begin{array}{c}\text { Coefficients of } \\
\text { linear expansion } \\
\text { at } 130^{\circ} \mathrm{C} \\
\times 10^{-5}\end{array}$ \\
\cline { 2 - 3 } & ${ }^{\circ} \mathrm{C}$ & 2.60 \\
\hline $\begin{array}{c}\text { Nano composite with } \\
\text { 3-D network structure }\end{array}$ & $>350$ & - \\
\hline
\end{tabular}

molecular hydrogen bridges between obtained copolymers. The flexural modulus for the bulk specimen with the phase structure of finely dispersed PBZT particles with $34.7 \mathrm{wt} \%$ amount of PBZT was nearly $7.4 \mathrm{GPa}$ the value for a graft copolymer reported by Dotrong et al. consisting of a PEK side chain attached to PBZT, ${ }^{13}$ with $36 \mathrm{wt} \%$ of PBZT. Table III indicates that the 3-D network structure leads to an outstandingly high efficiency of reinforcing materials, which in turn yields a higher flexural modulus than that of other specimens.

Mechanical Properties at High Temperature. Vicat softening temperatures are shown in Table III. Softening temperature was greatly improved for the 3-D network nano composite, such that the softening point was not below the molding temperature. The coefficient of linear expansion of the bulk specimen with the 3-D network decreased to nearly that of a light metal alloy (Table IV).

All the results suggest that various properties of the nano composite are improved considerably due to the formation of a fine 3-D network structure of rigid-rod reinforcing polymer fibrils, even with small amounts of reinforcing element, in contrast to the slight reinforcement effect of fine particles of reinforcing material dispersed throughout the nano composite. Essentially the same results were obtained by polymer blending of thermoplastic aromatic polyamide as a matrix polymer and a random copolymer as a reinforcing polymer consisting of a precursor of PBZT and a fragment in common with the matrix polymer, followed by conversion of the precursor to PBZT and molding using severally same method. ${ }^{10}$

\section{REFERENCES}

1. J. L. Kardos and J. Raisomi, Polym. Eng. Sci., 15, 183 (1995).

2. M. Hasegawa, M. Kochi, R. Yokota, and I. Mita, Eur. Polym. J., 25, 349 (1989).

3. K. Yamada, T. Mitsutake, M. Takayanagi, and T. Kajiyama, $J$. Macromol. Sci., A26, 891 (1989).

4. S. J. Krause, T. B. Haddock, G. E. Price, and W. W. Adams, Polymer, 29, 195 (1988).

5. K. S. Macturk, R. K. Eby, and B. L. Farmer, Polymer, 35, 53 (1994).

6. T. Hattori, H. Akita, M. Kakimoto, and Y. Imai, Macromolecules, 25, 3351 (1992).

7. T. Hattori, H. Akita, M. Kakimoto, and Y. Imai, J. Polym. Sci., Part A, Polym. Chem., 30, 197 (1992).

8. H. Akita, and T. Hattori, J. Polym. Sci., Part B, Polym. Phys., 37, 189 (1999).

9. H. Akita, H. Kobayashi, T. Hattori, and K. Kagawa, J. Polym. Sci., Part B, Polym. Phys., 37, 199 (1999).

10. H. Akita and H. Kobayashi, J. Polym. Sci., Part B, Polym. Phys., 37, 209 (1999).

11. T. D. Dang and F. E. Arnold, Mater. Res. Soc. Symp. Proc., 305, 49 (1993).

12. F. E. Arnold Jr. and F. E. Arnold, Adv. Polym. Sci., 117, 258 (1994).

13. M. H. Song, M. Dotrong, G. E. Price, M. H. Dotrong, U. M. Vakil, U. Santhosh, and R. C. Evers, Polymer, 35, 675 (1994).

14. S. Numata, K. Fujisaki, and N. Kinjoin, in "Polyimides," Vol. 1, K. L. Mittal, Ed., 1984, Part II, p 259. 